\title{
Regulation of Quantal Secretion from Developing Motoneurons by Postsynaptic Activity-Dependent Release of NT-3
}

\author{
Jau-Cheng Liou and Wen-Mei Fu \\ Pharmacological Institute, College of Medicine, National Taiwan University, Taipei, Taiwan 100
}

Neurotrophic factors derived from postsynaptic muscle cells may play important roles in the development of presynaptic neuronal functions. In 3-d-old Xenopus nerve-muscle cultures, embryonic spinal neurons that had made natural contact with co-cultured myocytes exhibited spontaneous release of larger packets of acetylcholine (ACh) quanta than those released by the isolated neurons having no contact with any myocyte. Treatment of isolated neurons with neurotrophin-3 (NT-3) for $2 \mathrm{~d}$ increased the average sizes of quantal ACh packets at newly formed nerve-muscle synapses, whereas treatment with antibody against NT-3 or with K252a, a specific inhibitor of tyrosine kinase receptors, decreased the quantal size at existing synapses, which suggests that NT-3 supplied by the postsynaptic muscle cell may be responsible for the development and maintenance of the quantal packets. The muscle effect seems to depend on synaptic activities mediated by postsynaptic ACh receptor channels, because chronic treatment of the culture with $D$-tubocurarine (D-TC) for $2 \mathrm{~d}$ resulted in a marked reduction of the quantal sizes, when assayed after extensive washing of the culture with Ringer's solution. The curare treatment did not affect the postsynaptic ACh receptor sensitivity, because iontophoretically applied ACh induced current responses similar to those of control. Finally, co-treatment of the culture with NT-3 and D-Tc reversed the effect of D-Tc on the quantal size, and this reversal effect was abolished when K252a was also applied concomitantly. Our results suggest that muscle-derived NT-3 participates in the maturation of normal transmitter packets in developing neurons, and the secretion of NT-3 depends on spontaneous synaptic activity.

Key words: neurotrophin-3; neurotrophic factor; neuromuscular junction; synaptogenesis; Xenopus laevis; neuronal activity
Successful synaptic transmission at the neuromuscular junction depends on the precise alignment of the nerve terminals with the postsynaptic specialization of the muscle fiber. It is increasingly apparent that this precision is achieved during development and maintained in the adult through signals exchanged between motoneurons and their target muscle fibers, which serve to coordinate their spatial and temporal differentiation (Hall and Sanes, 1993; Connor and Smith, 1994). Motoneurons communicate with muscle cells by secreting the neurotransmitter acetylcholine (ACh), as well as many other modulatory substances, including calcitonin gene-related peptide, agrin, ACh receptor-inducing activity, and ATP (Mason et al., 1984; Falls et al., 1990; Reist et al., 1992; Fu, 1995). The effects of neuron-derived factors on postsynaptic specializations have been reviewed extensively (Hall and Sanes, 1993; Jennings and Burden, 1993). The muscle cell, however, is not merely a passive recipient of inductive signals from the nerve terminals. Several aspects of neuronal differentiation seem to be dependent on retrograde signals from the target. In recent years, studies about synaptic modulation have focused attention on the characterization of proteins that mediate retrograde signals regulating the organization and function of nerve terminals. Neurotrophins are a potential class of factors.

The neurotrophins are a family of neurotrophic factors containing several closely related members: nerve growth factor (NGF), brain-derived neurotrophic factor (BDNF), neurotrophin-3 (NT-

\footnotetext{
Received Sept. 17, 1996; revised Jan. 14, 1997; accepted Jan. 22, 1997.

This work was supported by a grant from the National Science Council (NSC 84-2331-B002-109). We also thank Miss Yi-Ching Chiang for help with computer programs in statistics.

Correspondence should be addressed to Wen-Mei Fu at the above address. Copyright (C) 1997 Society for Neuroscience $0270-6474 / 97 / 172459-10 \$ 05.00 / 0$
}

3), NT-4/5, and NT-6 (Gotz et al., 1994; Heumann, 1994). The biological effects of these neurotrophins are mediated through three known tyrosine kinase (trk) receptors encoded by genes of the trk family (Chao, 1992; Barbacid, 1995). Although extensive studies have elucidated the powerful effects of neurotrophic factors on neuronal survival and differentiation of selected peripheral and central neurons (Korsching, 1993; Isackson, 1995), little is known about their effects in synaptic development and function. Studies of neurotrophin expression in adult mammals have shown that peripheral target tissues of spinal neurons express NT-3 and BDNF, whereas trkA and trkC mRNAs are expressed in motoneurons, raising the possibility that NT-3 or BDNF or both may act as target-derived trophic factors for spinal neurons. NT-3 or BDNF, but not NGF, rapidly potentiates the spontaneous and evoked transmitter release and has long-term effects on the maturation of neuromuscular synapses in Xenopus cell cultures, providing evidence for the functional regulation of developing synapses by neurotrophins (Lohof et al., 1993; Wang et al., 1995). We thus further investigated the role of muscle-derived neurotrophic factors in the synaptic regulation of embryonic motoneurons by using Xenopus nerve-muscle co-cultures.

Neuronal activity at developing synapses is crucial in synaptic maturation and competition as well as in the differentiation of postsynaptic properties (Sanes and Lawrence, 1983; Laufer and Changeux, 1989; Cramer and Mriganka, 1995). The levels of neurotrophin messenger RNA in visual cortex, hippocampal neurons, and skeletal muscle can be regulated further by synaptic electrical activity (Zafra et al., 1991; Funakoshi et al., 1995). Thus, a reciprocal regulation between neurotrophin expression and synaptic activity may operate to modulate synaptic efficacy. Results from the present study provide evidence that afferent activity plays 
a role in shaping connections in the neuromuscular synapse and suggest that endogenously released NT-3 from myocytes is involved in the maturation and/or functional maintenance of developing synapses.

\section{MATERIALS AND METHODS}

Cell culture. Xenopus nerve-muscle cultures were prepared as reported previously (Spitzer and Lamborghini, 1976; Anderson et al., 1977; Tabti and Poo, 1991). Briefly, the neural tube and the associated myotomal tissue of 1-d-old Xenopus embryos (stage 20-22) (Nieuwkoop and Faber, 1967) were dissected and dissociated in $\mathrm{Ca}^{2+}$ - and $\mathrm{Mg}^{2+}$-free Ringer's solution supplemented with $0.15 \mathrm{~mm}$ EDTA. The dissociated cells were plated on clean coverslips and used for experiments after incubation in culture medium for $3 \mathrm{~d}$ at room temperature. The culture medium consisted of $50 \%(\mathrm{v} / \mathrm{v})$ Ringer's solution $(115 \mathrm{~mm} \mathrm{NaCl}, 2 \mathrm{~mm} \mathrm{CaCl}, 2.5$ mм KCl, 10 mм HEPES, pH 7.6), 49\% L-15 Leibovitz medium (Sigma, St. Louis, MO), $1 \%$ fetal bovine serum (Life Technologies, Gaithersburg, $\mathrm{MD}$ ), and antibiotics (100 U/ml penicillin and $100 \mu \mathrm{g} / \mathrm{ml}$ streptomycin sulfate).

Drug administration. The cultures were plated, and after $24 \mathrm{hr}$ of incubation (defined as day 1 culture), the culture medium was renewed and NT-3 (PeproTech) or other drugs were bath-applied to the cultures. The cultures were used for experiments after an additional $2 \mathrm{~d}$ of incubation (defined as day 3 culture). The drugs were removed by several washes with Ringer's solution before the cultures were used for patchclamp experiments. Rabbit anti-NT-3 polyclonal antibody (Chemicon International, Temecula, CA) acts specifically against NT-3 and does not cross-react with BDNF or NGF.

Cell manipulation experiment. Cultures were viewed with phase-contrast optics of an inverted microscope (Nikon), and cell manipulation was performed with glass microelectrodes controlled by a micromanipulator (Narishige, Tokyo, Japan). In these cultures, motoneurons either form natural synapses resulting from random encounter of muscle cells by growing neurites or stay alone (myocyte-free, "naive" neuron). Isolated spherical myocytes (myoballs) were used in the experiment of manipulated contacts (Chow and Poo, 1985; Evers et al., 1989). Myoballs were first loosened from their attachment to the glass substratum by "rolling" the cell across the substratum surface with a heat-polished tight-seal micropipette. The loosening of the attachment allowed the myocyte to be lifted up from the substratum and then translocated to contact with the growth cone to form manipulated synapse. In some experiments, the postsynaptic myocyte of a natural synapse was mechanically destroyed by a micropipette, and the scattered debris of the myocyte was removed carefully. After $15 \mathrm{~min}$, another isolated myoball was then manipulated into contact with the so-called "vacated" nerve terminals to measure ACh release. The spontaneous synaptic current (SSC) recordings were then made 3 min after contact of the manipulated cell with naive or vacated nerve terminals, and the recordings lasted until $>180$ events were collected. The average time length for recording of the 180-plus events is $\sim 30 \mathrm{~min}$. These Xenopus cultures contain a heterogeneous population of neurons, and the fraction of ACh-releasing neurons, as evidenced by the appearance of SSC $(\sim 60 \%)$, is close to the previously suggested values for cholinergic neurons in this type of culture (Young and Poo, 1983; Chow and Poo, 1985).

Electrophysiology and data analysis. Gigaohm-seal whole-cell recording methods followed those described previously (Hamill et al., 1981; Young and Poo, 1983; Evers et al., 1989). Patch pipettes were pulled with a two-stage electrode puller (pp-83, Narishige), and the tips were polished immediately before the experiment with use of a microforge (MF-83, Narishige). SSCs were detected from the innervated myocytes of natural and manipulated synapses by whole-cell recording in the voltage-clamp mode. Recordings were made at room temperature in Ringer's solution, and the solution inside the recording pipette contained $150 \mathrm{~mm} \mathrm{KCl}, 1$ $\mathrm{mm} \mathrm{NaCl}, 1 \mathrm{~mm} \mathrm{MgCl}_{2}$, and $10 \mathrm{~mm}$ HEPES, $\mathrm{pH}$ 7.2. Evoked synaptic currents (ESCs) were elicited by stimulating presynaptic neurons at the soma with a heat-polished glass microelectrode (tip opening 1-2 $\mu \mathrm{M}$ ) filled with Ringer's solution. For suprathreshold stimulation of the neuron, a square current pulse of $0.3 \mathrm{msec}$ in duration and 2-4 $\mu \mathrm{A}$ in amplitude was applied through the pipette. Such currents generally induce twitch contraction of the muscle cell when they are applied to the soma of the innervating neuron. For the measurement of iontophoretic ACh-induced currents, conventional micropipettes were made and filled with $3 \mathrm{M} \mathrm{ACh}$. The resistance of the ACh pipette was in the range of $100-200 \mathrm{M} \Omega$ and required 2-6 nA braking current. The membrane currents induced by identical pulses of ACh (duration $2 \mathrm{msec}, 1 \mathrm{~Hz}$ ) applied at the myocyte surface were used to assay ACh sensitivity. The ACh pipette was positioned properly to get maximal responses, probably resulting from ACh receptor clusters, termed hot spots, in aneural muscle cells in culture (Fischbach and Cohen, 1973). In all recordings, the membrane currents were monitored by a patch-clamp amplifier (Axopatch $200 \mathrm{~A}$, filtered at $10 \mathrm{kHz}$ ). The currents were digitized (Neuro Dara DR 390) and stored on tape for later playback onto a storage oscilloscope or a polygraph (Gould RS3200) and also for amplitude analysis using SCAN computer program. The results were expressed as mean $\pm \mathrm{SE}(n)$. The $n$ represents the total number of recorded synapses or myocytes. The statistical significance was evaluated by Student's $t$ test. For comparison of SSC amplitude distribution, the composite graph of cumulative frequency of all SSC events was constructed, and only the synapse with a total number of events exceeding 180 was used for analysis $(n=5 \sim 10)$. The statistical difference between these graphs was tested by using the Kolmogorov-Smirnov test.

\section{RESULTS}

\section{Comparison of quantal sizes between myocyte-contacted and myocyte-free neurons}

In Xenopus nerve-muscle cultures, functional synaptic transmission can be detected within minutes after nerve-muscle contact (Kidokoro and Yeh, 1982; Xie and Poo, 1986; Evers et al., 1989), although morphological maturation of the synapse requires many days to complete (Takahashi et al., 1987; Buchanan et al., 1989). SSCs are readily detectable from the innervated muscle cell with the whole-cell voltage-clamp recordings. These currents have been shown to be caused by spontaneous ACh secretion from the neuron, because they are abolished by bath application of D-tubocurarine (D-Tc) and unaffected by tetrodotoxin, which blocks action potentials in neurons (Xie and Poo, 1986). To test whether muscle contact affects the secretory properties of the presynaptic neuron, we measured the spontaneous transmitter release either at natural synapses formed in 3-d-old Xenopus nerve-muscle cultures or at synapses made by manipulating the contact of spherical myocytes with isolated (myocyte-free, "naive") neurons in the same culture. The amplitude distribution of SSCs provides a useful indication of the maturation of presynaptic ACh secretion mechanisms. At mature neuromuscular junctions, the distribution of SSC amplitude exhibits a bell-shaped profile, reflecting a well defined ACh quantal packet in the presynaptic nerve terminals. The distribution of SSC amplitude at developing neuromuscular synapses, however, is usually skewed toward small amplitudes, and a transition from a skewed to a bell-shaped distribution accompanies synaptic maturation (Kidokoro, 1984; Lu et al., 1992). Examples of SSCs recorded at natural synapse in 1-d- and 3-d-old Xenopus cultures are shown in Figure 1. The amplitude distribution at $3 \mathrm{~d}$ synapse showed a higher proportion of events with larger amplitude (Fig. $1 c-e$ ). The mean amplitudes were $104.6 \pm 5.7 \mathrm{pA}(n=23)$ and $155.3 \pm 19.1 \mathrm{pA}(n=27)$ for day 1 and day 3 synapses, respectively.

The amplitude of SSCs depends on the amount of ACh contained in each secretory packet as well as the ACh receptor density in the postsynaptic membrane. To exclude the postsynaptic contribution to the size distribution of SSCs, the postsynaptic myocyte of natural synapses in day 3 cultures was removed mechanically by a micropipette, and another isolated neuron-free myocyte was manipulated to contact with the "vacated" nerve terminals. As shown in Figure $2 b$ (top trace), the amplitude of SSCs recorded at the manipulated myocyte made with the vacated nerve terminals was smaller than that observed at the natural synapse before myocyte removal (Fig. 1b, right). The difference may be attributed to the clustering of $\mathrm{ACh}$ receptor at the postsynaptic site of natural synapse in comparison with the more 


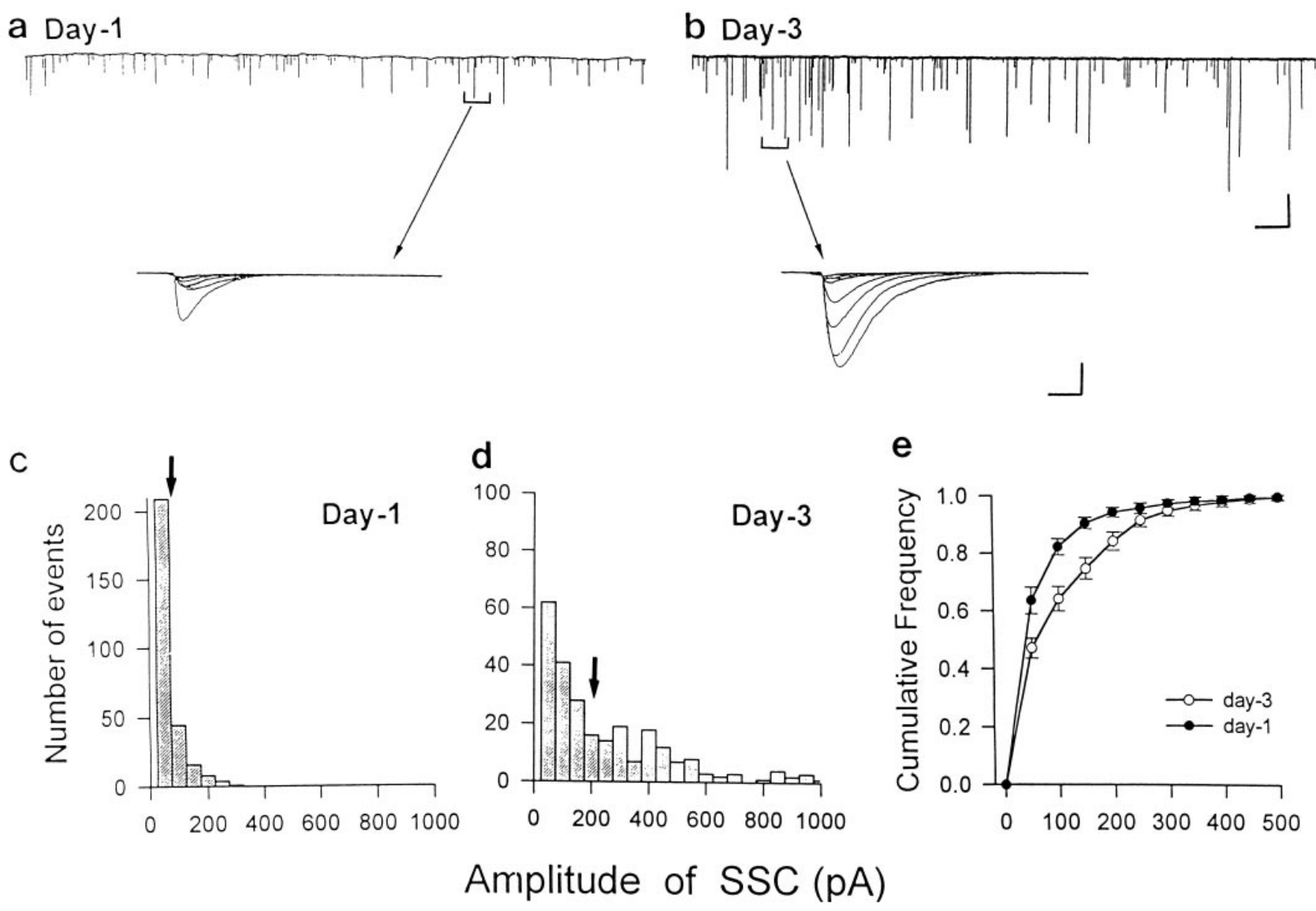

Figure 1. SSCs recorded from day 1 and day 3 natural synapses. The continuous trace depicts the membrane currents recorded from an innervated muscle cell in day $1(a)$ or day $3(b)$ Xenopus culture, using the whole-cell recording method $\left(V_{\mathrm{H}}=-70 \mathrm{mV}\right)$. The superimposed traces of 10 continuous events were shown below at higher time resolution. Calibrations: $200 \mathrm{pA}, 40 \mathrm{sec}$, and $230 \mathrm{pA}, 4 \mathrm{msec}$ for the slow and fast traces, respectively. $c$, $d$, Histograms of the amplitude distribution of all SSC events observed from $a$ and $b$, respectively. Arrows indicate the mean values. $e$, Composite graphs of SSC amplitude distribution for data obtained from seven synapses. The Cumulative Frequency refers to the proportion of the total events.

scattered distribution of ACh receptors in the manipulated myoball (Kidokoro et al., 1980). Furthermore, we found that the mean amplitude of SSC observed at the vacated nerve terminals, i.e., $75.8 \pm 7.4 \mathrm{pA}(n=10)$, was significantly higher than that observed at the nerve terminals of naive neurons in the same $3 \mathrm{~d}$ cultures (Fig. $2 b$, bottom trace), which has a mean value of $50.9 \pm 6.4 \mathrm{pA}$ $(n=9$; Table 1$)$. Comparison of the SSC amplitude distribution at synapses made with vacated versus naive nerve terminals (Fig. $2 c$ ) indicates that the vacated nerve terminals more frequently exhibited spontaneous release of ACh quanta of larger sizes. The amplitude distributions for a large number of manipulated synapses were summarized by the cumulative frequency curves shown in Figure $2 d$. The difference between the two curves is statistically significant ( $p<0.05$; Kolmogorov-Smirnov test). Because similar isolated myocytes were used in detecting ACh secretion, these results suggest that the vacated nerve terminals are capable of secreting larger quantal packets than the naive nerve terminals that had no contact with any myocyte. Finally, in contrast to that found for the SSC amplitude, we found that there is no difference between the SSC frequencies observed at the vacated and naive nerve terminals, which were $0.11 \pm 0.05 \mathrm{~Hz}(n=11)$ and $0.09 \pm$ $0.05 \mathrm{~Hz}(n=9)$, respectively. The SSC frequency of natural synapse that correlated with the vacated synapse was $0.23 \pm 0.12$ Hz. Moreover, the smaller quantal size was also observed at naive nerve terminals of a neuron that had made contact with the myocyte and released ACh at other axon branches. The SSC amplitude recorded from three manipulated synapses that formed with such naive nerve terminals was $55.1 \pm 0.2 \mathrm{pA}$. Thus, prolonged synaptic contact with the myocyte results in an increase in the size of ACh quantal packets of the presynaptic nerve terminals.

Table 1. Summary of the potentiating effect of NT-3 at developing motoneurons

\begin{tabular}{|c|c|c|}
\hline & \multicolumn{2}{|c|}{ SSC amplitude (pA) } \\
\hline & Control & NT-3 treatment \\
\hline \multicolumn{3}{|l|}{ Manipulated synapse } \\
\hline Naive nerve terminal & $50.9 \pm 6.4(9)$ & $75.3 \pm 5.8(8)^{*}$ \\
\hline Vacated nerve terminal & $75.8 \pm 7.4(10)$ & ND \\
\hline Natural synapse & $155.3 \pm 19.1(27)$ & $184.2 \pm 33.1(22)$ \\
\hline Natural synapse treated with $\mathrm{D}-\mathrm{Tc}$ & $48.9 \pm 3.4(12)$ & $110.4 \pm 13.2(9)^{*}$ \\
\hline
\end{tabular}

Drugs were bath-applied to day 1 cultures and removed by several washes with Ringer's solution on day 3 for the recordings of spontaneous synaptic currents (SSCs). SSCs were recorded from either manipulated synapses or natural synapses by whole-cell voltage-clamped myocyte $\left(\mathrm{V}_{\mathrm{H}}=-70 \mathrm{mV}\right)$.

The values were shown as mean $\pm \mathrm{SE}(n) . n$, Number of synapses.

ND, Not determined.

${ }^{*} p<0.05$ as compared with control. 
a

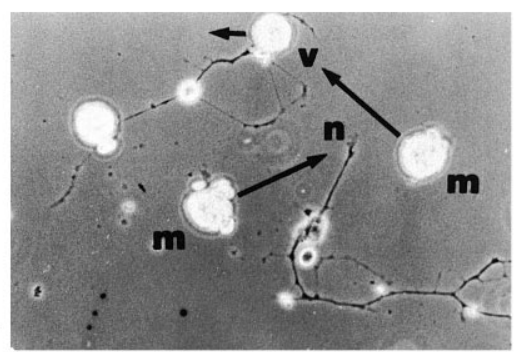

b

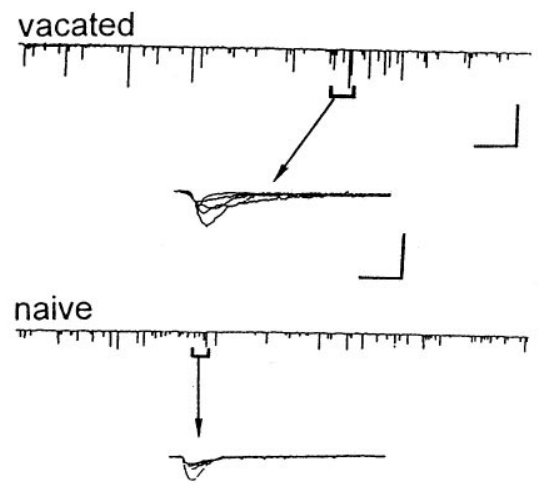

Figure 2. Effect of myocyte contact on the spontaneous ACh release from nerve terminals in day 3 Xenopus cell cultures. $a$, Phase-contrast photograph shows that the motoneuron either may form natural synapses with myocytes (left) or stay alone ( $n$, naive) (right). A myocyte was manipulated into contact with the nerve terminals of naive neuron $(n)$ for the detection of $\mathrm{ACh}$ release. For natural synapses, the postsynaptic myocyte was mechanically destroyed and the scattered debris of the myocyte was then removed carefully by using a micropipette (long arrow), and another isolated neuron-free myocyte $(m)$ was manipulated into contact with the "vacated" $(v)$ nerve terminals. $b$, Spontaneous ACh release was recorded in either naive neuron (bottom trace) or vacated nerve terminals (top trace) by using an isolated myocyte manipulated into contact as a detector for the secretion $\left(V_{\mathrm{H}}=-70\right.$ $\mathrm{mV})$. Insets represent superimposed traces of five continuous SSCs at higher time resolution. Note the smaller amplitude of SSCs at naive synapse compared with that at vacated synapse. Calibrations: $150 \mathrm{pA}, 40$ $\mathrm{sec}$, and $150 \mathrm{pA}, 5 \mathrm{msec}$ for slow and fast traces, respectively. $c$, Histograms of the amplitude distribution for all SSC events observed from $b$. Arrows indicate the mean values. $d$, Cumulative frequency of amplitude distribution of all SSC events obtained from vacated $(n=10)$ and naive $(n=9)$ nerve terminals.

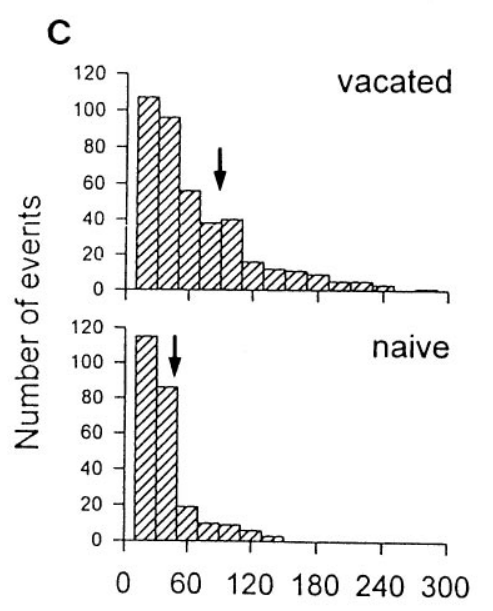

d

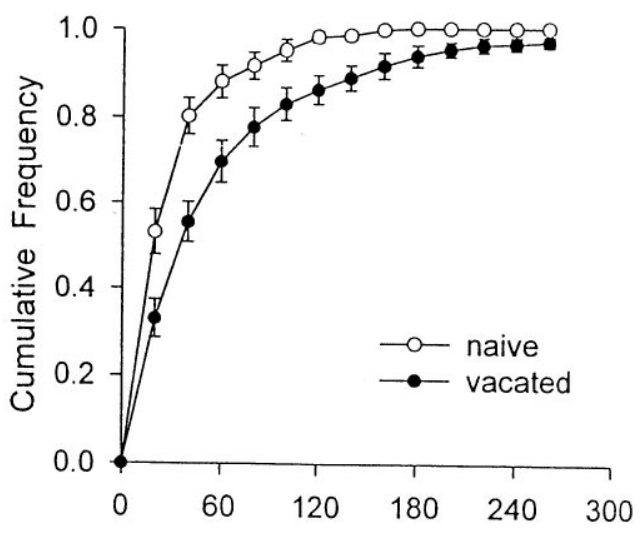

Amplitude of SSC (pA)

\section{Effect of NT-3 on isolated neurons}

The above studies indicate that muscle contact influenced the status of quantal secretion machinery in the presynaptic nerve terminals. What is the nature of the factor involved in this retrograde interaction? NT-3, a member of the neurotrophin family, is detected in the muscle cell (Henderson et al., 1993; Koliatsos et al., 1993). Acute application of NT-3 to developing Xenopus neuromuscular synapses greatly elevates the frequency of spontaneous ACh secretion (Lohof et al., 1993). We thus examined the potential role of NT-3 in modulating the size of ACh quanta in these Xenopus cultures. One-day-old cultures were treated with NT-3 (2 nM), and the size and distribution of SSC amplitude were determined $2 \mathrm{~d}$ later at naive nerve terminals of isolated neurons by manipulation of an isolated myocyte of the same culture to contact and detect ACh secretion. As illustrated in Figure $3 a$, we found that the mean amplitude of SSCs was increased in NT-3treated neurons $(75.3 \pm 5.8 \mathrm{pA} ; n=8$; Table 1). Amplitude distribution indicated that there were more ACh quanta of larger sizes at NT-3-treated neurons (Fig. 3b). The increasing effect of NT-3 on SSC amplitude of naive nerve terminals was antagonized by simultaneous treatment with polyclonal antibody against NT-3 (1:200) (SSC amplitude was 54.9 $\pm 5.6 \mathrm{pA} ; n=4)$. To exclude the possible direct effect of NT-3 on myocytes, the day 3 untreated myoball of a separate culture was detached and carefully translocated into the thoroughly washed NT-3-treated culture to form manipulated synapse with naive neuron to detect ACh secretion. The SSC amplitude was $85.9 \pm 2.6(n=3)$. Thus exogenously applied NT-3 facilitated the development of a more mature pattern of quantal secretion.

\section{Involvement of NT-3 at natural synapses}

The above studies showed that NT-3 treatment of isolated neurons resulted in an increase in ACh quanta size similar to that resulting from myocyte contact. We further explored the possibility that muscle-derived NT-3 was responsible for the effect of prolonged muscle contact on the quantal size by examining the effect of exogenously supplied NT-3 and NT-3 antibodies on the quantal size of natural synapses in these Xenopus nerve-muscle cultures. NT-3 was added to the cultures on day 1, and SSCs were recorded at the natural synapses on day 3. We found that the mean SSC amplitude at NT-3-treated natural synapses (184.2 \pm $33.1 \mathrm{pA} ; n=22$ ) was not significantly different from synapses in 3 d cultures not treated with NT-3 (155.3 $\pm 19.1 \mathrm{pA} ; n=27$; Table 1). When a polyclonal antibody against NT-3 was added to the culture instead of NT-3, however, we found that the mean SSC amplitude, $80.0 \pm 7.2 \mathrm{pA},(n=13)$, was significantly smaller than that found at the untreated synapses in $3 \mathrm{~d}$ cultures (Fig. $4 a$ ). The mean SSC amplitude in the cultures treated with preimmune serum was $125.3 \pm 2.7 \mathrm{pA}(n=3)$. Similarly, chronic treatment of the culture for $2 \mathrm{~d}$ with $\mathrm{K} 252 \mathrm{a}(1 \mu \mathrm{M})$, a trk receptor inhibitor, 
a

Control
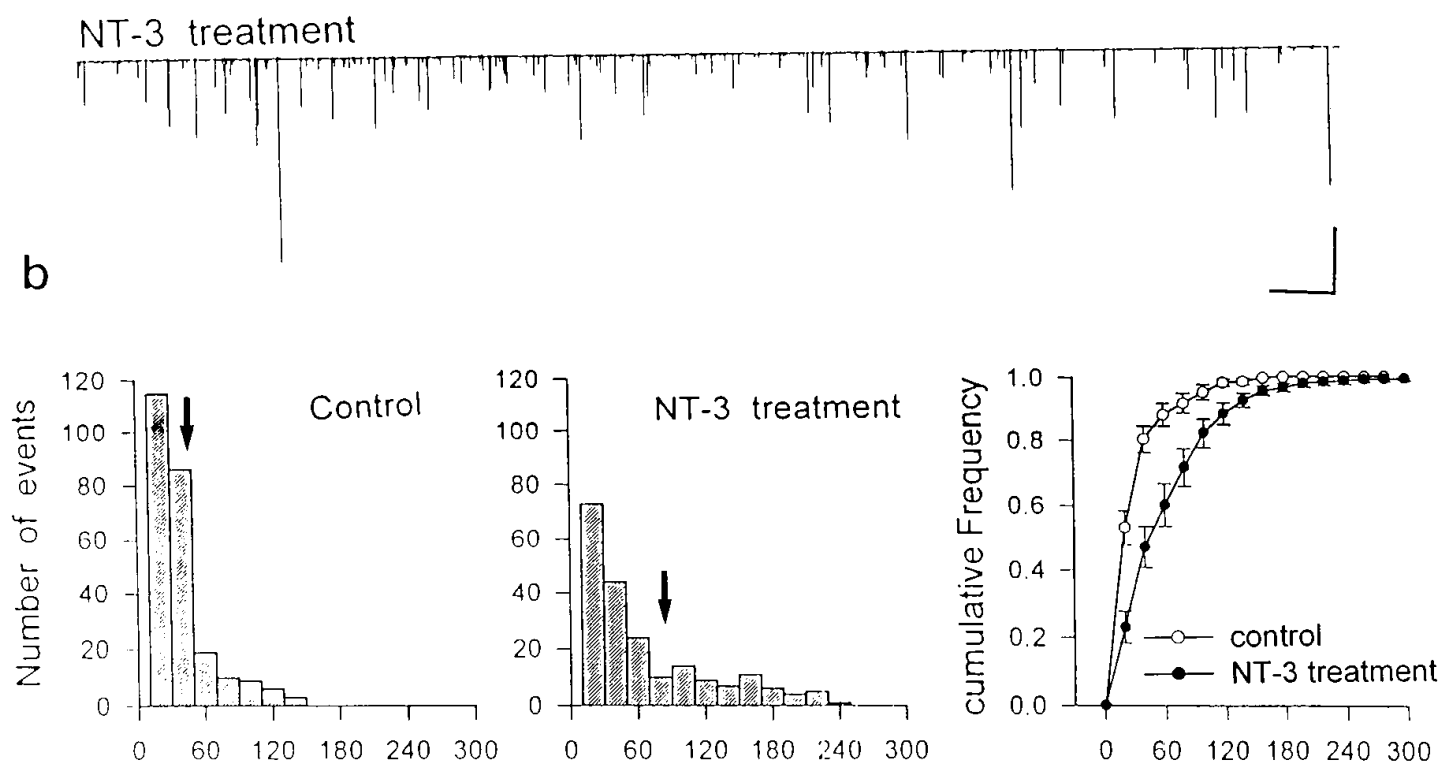

Amplitude of SSC (pA)

Figure 3. Effect of NT-3 chronic treatment on the spontaneous ACh release of naive nerve terminals in day 3 Xenopus cell cultures. $a$, One-day-old cultures were treated with NT-3 $(2 \mathrm{nM})$, and a myoball was detached from culture substratum and moved to contact with the naive nerve terminals to build manipulated synapse at day 3 . The myocyte was whole-cell voltage-clamped at $-70 \mathrm{mV}$ to record SSCs. Note an increase in the mean amplitude of SSCs at the synapse treated with NT-3 (bottom trace) compared with that at control (top trace). Calibration: $200 \mathrm{pA}, 40$ sec. $b, c$, SSC amplitude distribution of manipulated synapse at control or NT-3-treated naive nerve terminals. Arrows indicate the mean values. $d$, Cumulative frequency of amplitude distribution of all SSC events obtained from control $(n=5)$ and NT-3-treated $(n=8)$ neurons.

resulted in a reduction of the mean SSC amplitude at synapses in $3 \mathrm{~d}$ cultures to $55.8 \pm 3.5 \mathrm{pA}(n=11$; Fig. $4 a)$. In contrast to their effects on SSC amplitudes, the frequency of SSCs was not affected significantly by either the antibody or the K252a treatment, whereas NT-3 treatment induced an increase in the frequency (Fig. 4b).

The effect of chronic treatments with NT-3, NT-3 antibody, or $\mathrm{K} 252 \mathrm{a}$ on impulse-evoked ACh release at these developing synapses was also examined in 3-d-old cultures. The presynaptic neuron was stimulated extracellularly at the soma to initiate action potentials at a frequency of $0.2 \mathrm{~Hz}$, and ESCs were recorded from the innervated muscle cells in 3-d-old Xenopus cultures by the whole-cell voltage-clamp method. As shown in Figure 5, we found that mean ESC amplitude in NT-3-treated cultures was $4.57 \pm 0.85 \mathrm{nA}(n=7)$, which was not significantly different from that of the synapses in untreated $3 \mathrm{~d}$ cultures $(3.97 \pm 0.38$ $\mathrm{nA} ; n=4)$. Two day treatments with antibody to NT-3 or K252a, however, significantly reduced the mean ESC amplitude to $2.44 \pm$ $0.47 \mathrm{nA}(n=8)$ and $1.59 \pm 0.29 \mathrm{nA}(n=5)$, respectively. These results on ESCs are consistent with the notion of an NT-3dependent increase in the size of ACh quanta.

\section{Effects of D-Tc on natural synapses}

Synaptic activity is known to play a critical role in regulating the pattern of synaptic connections (Goodman and Shatz, 1993). We have tested whether the retrograde effect of muscle cell on pre- synaptic nerve terminal secretion properties depended on postsynaptic muscle activity. The postsynaptic activity in Xenopus nerve-muscle cultures was blocked by chronic treatment with $\mathrm{D}-\mathrm{Tc}(50 \mu \mathrm{M})$. The drug was added to day 1 cultures when natural synapse has established, and the synaptic function was assayed on day 3, after the cultures were washed extensively with fresh Ringer's solution to remove D-Tc. As shown in Figure $6 a$, the SSCs recorded from natural synapses in D-Tc-treated cultures showed a much smaller mean amplitude (48.9 $\pm 3.4 \mathrm{pA} ; n=12$; Table 1), and the amplitude distribution became markedly skewed toward smaller amplitude, similar to that observed at newly made synapses on naive neurons (Fig. 2). Representative amplitude histograms and a composite cumulative frequency plot are shown in Figure $6 b-d$. Compared with that of control synapses not exposed to D-Tc, quantal sizes were clearly shifted toward smaller amplitudes.

To test whether the reduced quantal size was attributable to a reduction of $\mathrm{ACh}$ receptor sensitivity in postsynaptic muscle cell as a result of D-Tc treatment, myocyte responses induced by focal iontophoretic application of identical ACh pulses on the postsynaptic myocyte surface were compared (Fig. 6a). The average ACh-induced myocyte responses in D-Tc-treated cultures were similar to those in untreated cultures: $0.85 \pm 0.16 \mathrm{nA}(n=9)$ and $0.94 \pm 0.21 \mathrm{nA}(n=5)$, respectively. To further eliminate the possible postsynaptic inhibitory effect of chronic D-Tc treatment, 

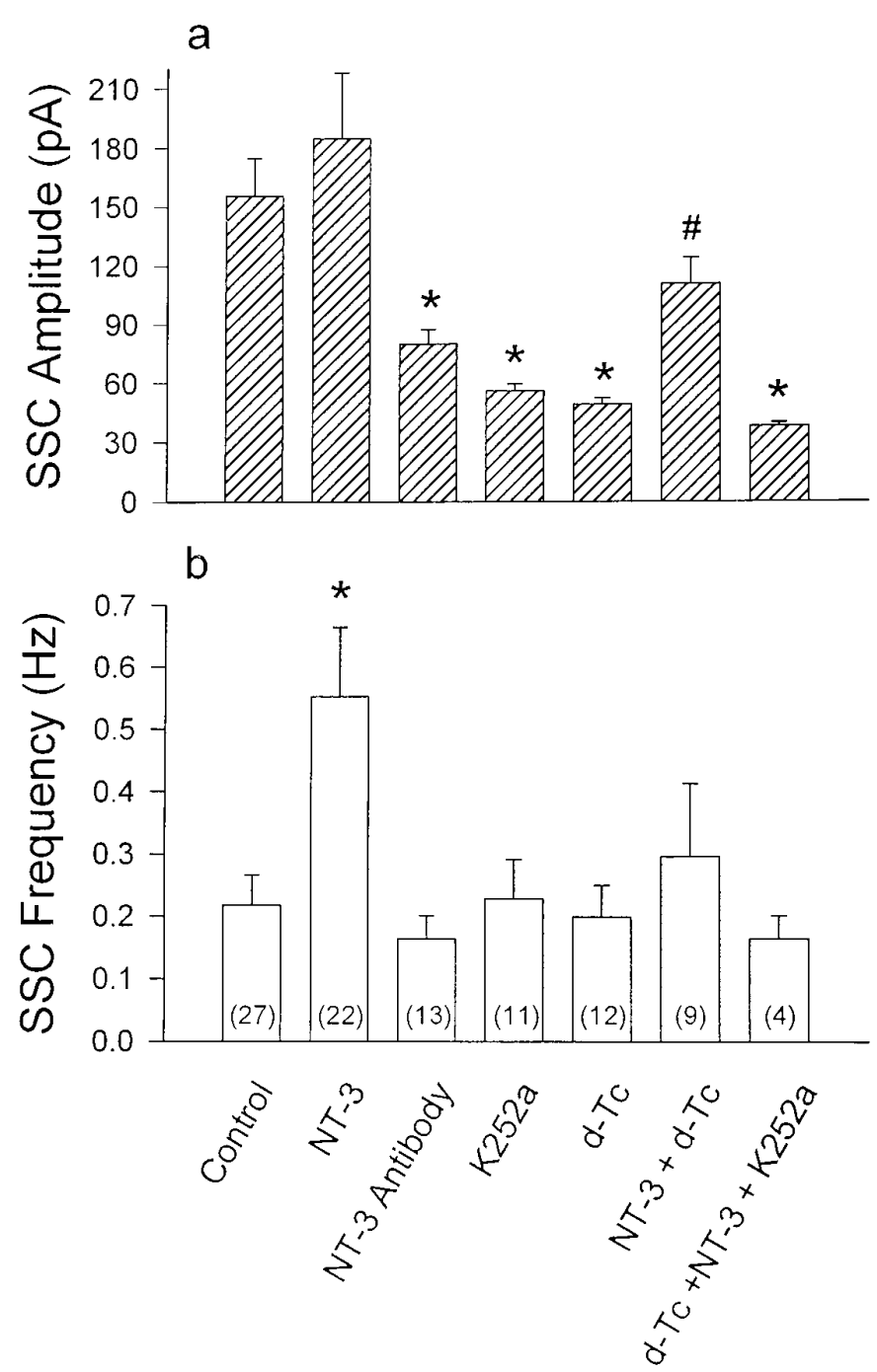

Figure 4. Summary of the change of SSC amplitude and frequency at natural synapse. Day 1 cultures were treated with various kinds of drugs as indicated in the figure (NT-3, $2 \mathrm{nM}$; K252a, $1 \mu \mathrm{M}$; D-Tc, $50 \mu \mathrm{M}$; and NT-3 antibody, 1:200). The amplitude and frequency of SSCs of natural synapses were measured at day 3 after washout of the drugs. The error bars represent SEM, and the number of synapses tested in each group is indicated in parentheses. ${ }^{*}, p<0.05$ as compared with control; \#, $p<0.05$ as compared with the D-Tc-treated group (Student's $t$ test).

the following experiment was performed. After the recording of SSCs from natural synapses of control or D-Tc treatment, the postsynaptic myocyte was removed mechanically, and a myoball unexposed to D-Tc (from a separate culture) was manipulated into contact with the vacated nerve terminals to examine ACh secretion. We found that the mean SSC amplitude observed for the D-Tc-treated nerve terminals $(27.6 \pm 1.2 \mathrm{pA} ; n=12)$ was significantly smaller than that observed at vacated nerve terminals in day 3 cultures not exposed to D-Tc $(75.8 \pm 7.4 \mathrm{pA} ; n=8)$.

The results shown above suggest that postsynaptic activity is important in the regulation of presynaptic quantal secretion at developing motoneurons. We thus increased muscle activity by using veratridine. Concomitant treatment of day 1 cultures with veratridine $(1 \mu \mathrm{M})$ and D-Tc partially antagonized the D-Tc effect at natural synapse: the SSC amplitude was $86.4 \pm 8.6 \mathrm{pA}(n=8)$ (D-Tc alone: $48.9 \pm 3.4 \mathrm{pA} ; n=12$ ) on day 3 . The antagonizing effect did not result from direct action of veratridine on neurons, because the SSC amplitude of manipulated synapse in naive neuron was still $48.2 \pm 4.3 \mathrm{pA}(n=6)$, which was not significantly different from the control $(50.9 \pm 6.4 \mathrm{pA} ; n=9)$.

\section{Exogenous NT-3 reduces D-Tc effects}

The effect of chronic treatment of D-Tc on the size of ACh quanta suggests that postsynaptic activity is required for the retrograde effect on the presynaptic nerve terminals. If the retrograde factor were NT-3, the exogenously supplied NT-3 would obliterate the $\mathrm{D}-\mathrm{Tc}$ effect. A group of cultures was treated simultaneously with both D-Tc and NT-3 (2 nM); the mean SSC amplitude recorded at natural synapses in these cultures was $110.4 \pm 13.2 \mathrm{pA}(n=9)$, which is substantially higher than that found in cultures treated with D-Tc alone (48.9 $\pm 3.4 \mathrm{pA} ; n=12$; Fig. 4$)$. Comparison of the SSC amplitude between NT-3 + D-Tc and NT-3 alone showed that the difference was not significant $(p>0.05)$. The mean amplitude of the ESCs in NT-3 and D-Tc co-treated cultures was $3.34 \pm 0.37 \mathrm{nA}(n=3)$, which is also significantly higher than that found in cultures treated with D-Tc alone $(1.31 \pm 0.12 \mathrm{nA} ; n=6$; Fig. 5). Thus, exogenous NT-3 had substantially reversed the effect of D-Tc in reducing the quantal size and the evoked response. Furthermore, the effect of NT-3 was specifically mediated by trk receptor, because adding trk receptor inhibitor $\mathrm{K} 252 \mathrm{a}$ to the cultures in the presence of NT-3 and D-Tc prevented the reversal effect introduced by NT-3 (Fig. 4).

\section{DISCUSSION}

The main finding of this study is that muscle cell-derived factor is involved in the regulation and maintenance of the quantal size of synaptic transmission at developing motoneurons. The smaller SSC amplitude of manipulated synapse derived from myocyte-free naive neurons was predominantly a result of reduction in presynaptic ACh quantal size. A larger SSC amplitude was still obtained in myocytes that were manipulated into contact with vacated nerve terminals, excluding the possible postsynaptic effect, because the manipulated myocyte has a more even distribution of $\mathrm{ACh}$ receptors. These results indicate that a motoneuron contacted by a myocyte releases $\mathrm{ACh}$ in larger quantal size. The smaller quantal size observed at myocyte-free nerve endings of a neuron that had made contact with a myocyte at other axon branches further supports this notion.

The efficacy of synaptic transmission is susceptible to activitydependent modulation (Bear and Malenka, 1994). In developing nervous systems, the pattern of electrical activity also exerts a critical influence on the stabilization and elimination of nerve connections (Goodman and Shatz, 1993). Synapses can form in the presence of D-Tc, and activity blockade causes an increase in the number of synapses (Dahm and Landmesser, 1991). Here we showed that prolonged blockade of neuromuscular transmission by $\mathrm{D}-\mathrm{Tc}$ decreased the presynaptic quantal size markedly, indicating that some maturational aspects were retarded by D-Tc treatment. The reduction of SSC amplitude after chronic D-Tc treatment was not likely a result from the change of postsynaptic ACh responses or incomplete washout of D-Tc, because there was no significant change in myocyte surface ACh sensitivity, as assayed by ACh iontophoresis. It seems that the lower amplitude of SSC could be attributable to a smaller amount of ACh per quantal package in the presynaptic terminals. The smaller SSC amplitude at vacated nerve terminals that made contact with a myoball unexposed to D-Tc further supports the notion that prolonged neuromuscular blockade prevents the maturation of nerve terminals. The larger SSC amplitude distribution in natural synapses 
a

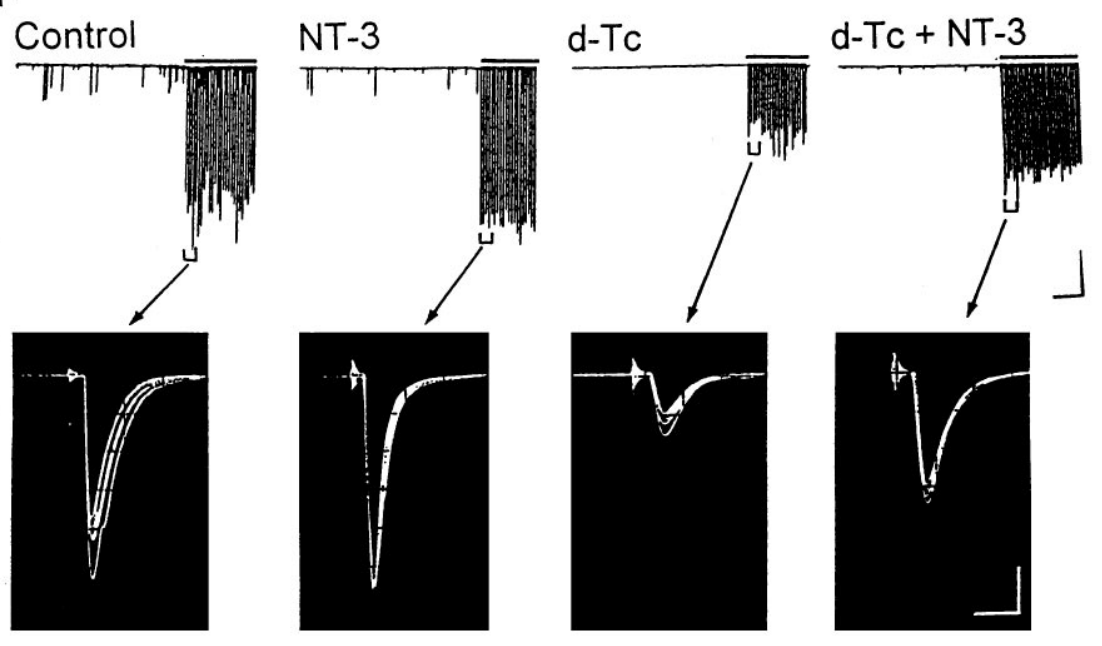

b

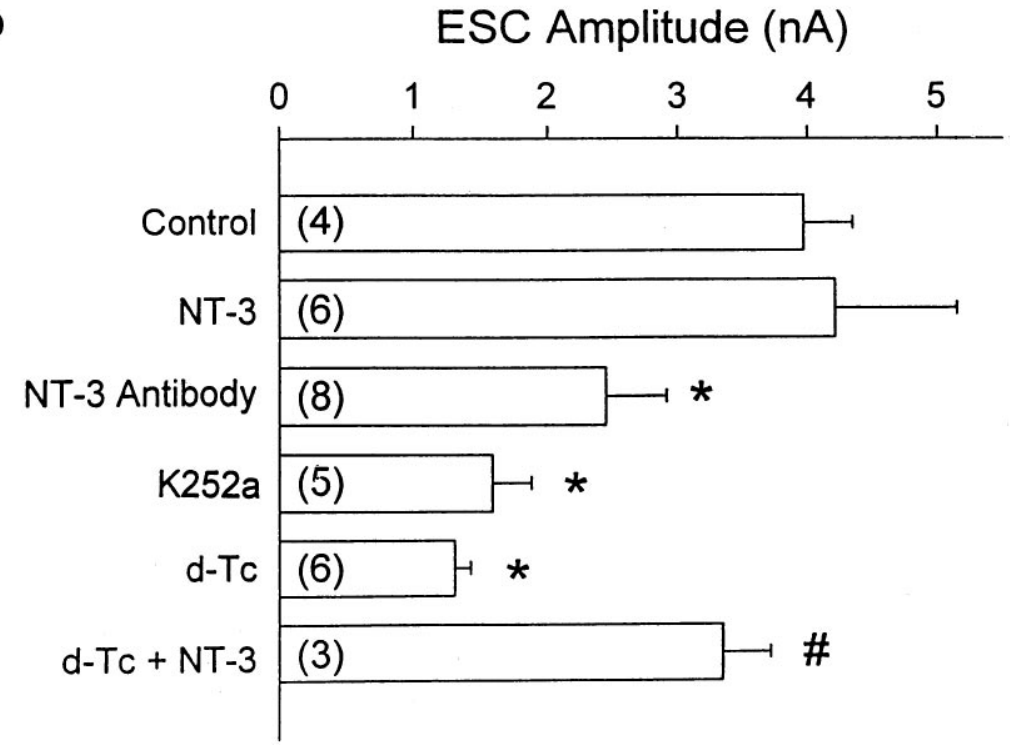

Figure 5. Effect on evoked ACh release in Xenopus cell cultures. $a$, Day 1 cultures were treated with various kinds of drugs as indicated in the figure (concentrations were the same as in Fig. 4), and ESCs of natural synapse were recorded with whole-cell voltageclamped myocytes $\left(V_{\mathrm{H}}=-70 \mathrm{mV}\right)$ at day 3 , after washout of the drugs. The presynaptic neuron was stimulated with an extracellular microelectrode at the soma to fire action potentials at a rate of $0.2 \mathrm{~Hz}$. Oscilloscopic traces of five superimposed ESCs are shown below. Calibrations: $120 \mathrm{nA}, 100 \mathrm{sec}$, and $1 \mathrm{nA}$, $10 \mathrm{msec}$, for the slow and fast traces, respectively. $b$, Bar graphs for quantitative comparison of ESC amplitudes. The numbers associated with the data refer to the total number of synapses examined. *, $p<0.05$ as compared with control; \#, $p<0.05$ as compared with the D-Tc-treated group (Student's $t$ test). whose innervated myocytes showed spontaneous contraction is also consistent with this activity-dependent regulation of quantal secretion (data not shown). The smaller amplitude of ESC after chronic treatment with D-Tc may also result from the reduced quantal size, but the possibility of reduction of quantal content in response to evoked release of neurons cannot be excluded at this time. Veratridine effectively antagonized the SSC amplitudereductive effect of $\mathrm{D}$-Tc, which further supports the notion that muscle activity is important in the regulation of quantal secretion. Consistent with this result, blockade of neuromuscular transmission by the inhibition of ACh receptor with $\alpha$-bungarotoxin $(\alpha$ BuTx) for 6-7 d after birth will bring about the death of motoneurons that supply the muscle (Greensmith and Vrbova, 1989). The role of synaptic activity in the maintenance of synaptic function was demonstrated further at the adult neuromuscular junction where synaptic transmission in one part of the endplate was eliminated by selective application of $\alpha$-BuTx (Balice-Gordon and Lichtman, 1994). Thus, the activity level at and within a synapse may directly influence the formation and maintenance of synaptic sites.
Muscle-derived retrograde factors would be likely candidates to mediate this synaptic remodeling, because muscle activity has a well documented role in controlling the transcription and expression of several muscle fiber proteins (Goldman et al., 1988; Eftimie et al., 1991). Extensive studies of neurotrophin expression in the adult mammal have shown that peripheral target tissues of spinal neurons express NT-3 and BDNF, and the observation that BDNF and NT-3 are transported retrogradely to the ventral spinal cord raises the possibility that NT-3 or BDNF or both may act as target-derived trophic factors for spinal neurons (Distefano et al.,1992; Henderson et al., 1993). A reciprocal regulation between neurotrophin expression and synaptic activity may operate to modulate synaptic efficacy. Our results show that chronic treatment with NT-3 modulates the quantal secretion at these developing synapses at either "naive" nerve terminals or natural synapses that were chronically treated with D-Tc. Exactly how NT-3 enhances the quantal size in myocyte-free neuron is unknown. Earlier works (Lohof et al.,1993; Berninger and Poo, 1996) showed that acutely applied NT-3 increased the SSC frequency but did not affect the size of the SSCs, suggesting that the quantal 
Figure 6. Effect of D-Tc chronic treatment on the SSCs of natural synapse. Day 1 Xenopus cell cultures were treated with D-Tc $(50 \mu \mathrm{M})$ and washed with Ringer's solution at day 3 before the electrophysiological experiments. a, Continuous trace depicts membrane currents recorded from a whole-cell voltageclamped myocyte $\left(V_{\mathrm{H}}=-70 \mathrm{mV}\right)$, which was innervated by control neuron (top) or chronically treated with D-Tc (bottom). Iontophoretic application of $\mathrm{ACh}$ at the myocyte surface was performed, as shown by the solid bar. Five continuous superimposed traces of SSCs or iontophoretic ACh-induced currents were shown below at higher time resolution. Calibrations: $200 \mathrm{pA}, 20 \mathrm{sec}$, and $100 \mathrm{pA}, 10 \mathrm{msec}$, for slow and fast traces, respectively. $b$, $c$, Histograms of SSC amplitude distribution of the same natural synapses as shown in $a$. Arrows indicate the mean values. $d$, Cumulative frequency of amplitude distribution of all SSC events obtained from control $(n=8)$ and D-Tc-treated $(n=7)$ synapses.

\section{a Spontaneous Synaptic Currents Control}

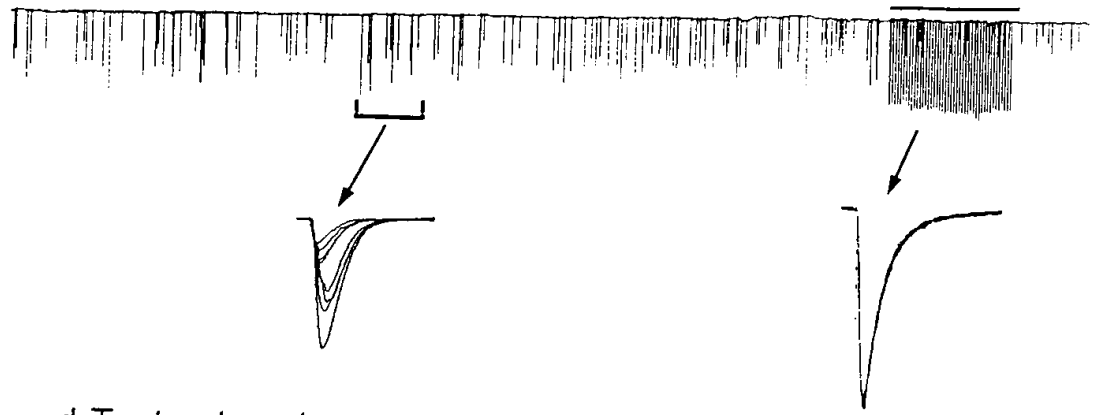

\section{d-Tc treatment}

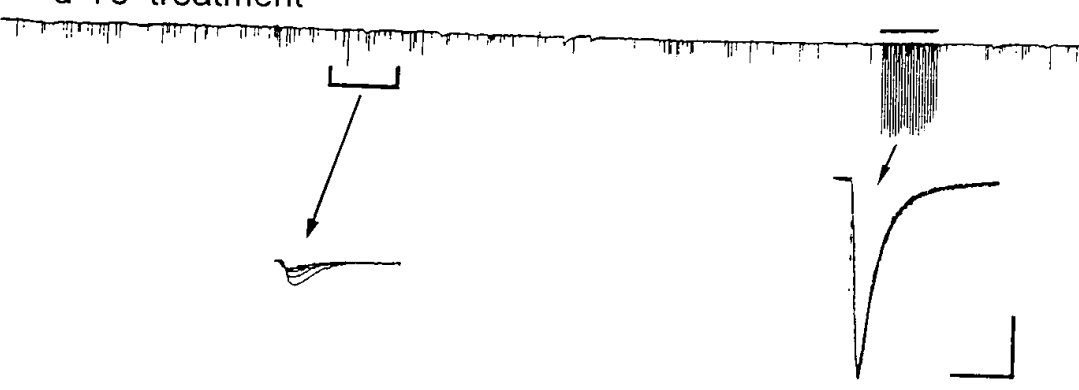

b

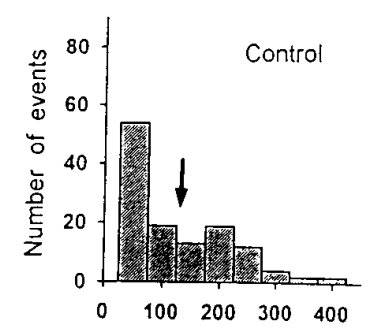

C

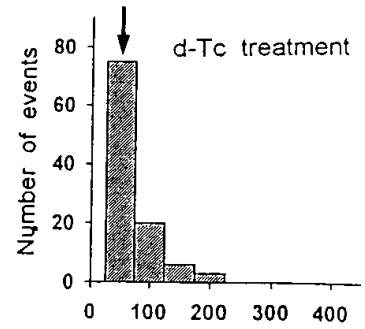

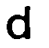

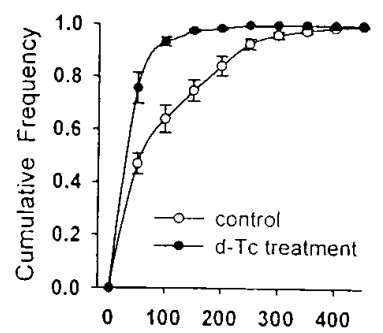

Amplitude of SSC $(p A)$ size was chronically regulated by NT-3. It has been demonstrated that NT-3 induced the choline acetyltransferase activity in the motor nerve terminals (Wong et al., 1993). It is thus possible that more ACh molecules are synthesized in the presence of neurotrophins. Alternatively, an enhancement of transporter of the synaptic vesicle to increase the number of ACh molecules packed in each vesicle may also explain the larger quantal size after NT-3 treatment. Studies using chimeric receptor approaches, specific antibodies against the extracellular receptor domain, and gene knock-out experiments of trk receptors have shown that trk is essential and sufficient to mediate the characteristic neurotrophin functions such as survival of neurons or induction of neurite outgrowth (Lamballe et al., 1991; Klein et al., 1994; Snider, 1994). Involvement of endogenously released NT-3 from myocyte in the retrograde presynaptic regulation comes from the antibody experiment. Chronic treatment for $2 \mathrm{~d}$ with polyclonal antibody specific for NT-3 attenuated the SSC amplitude of natural synapses at day 3 and clearly indicated that endogenously released NT-3 is involved in the dynamic interactions between presynaptic motoneurons and postsynaptic muscle cells. Moreover, the observation that pharmacological blockade of trk activity by chronic treatment with K252a also markedly decreased the quantal size of natural synapse in day 3 cultures further strengthens the notion that NT-3 may play an important role in the maintenance of synaptic function at developing nervous systems. Exogenous application of NT-3 to cultures on day 1 did not further increase SSC amplitude on day 3 , which suggests that the endogenously released neurotrophins from myocyte may be sufficient to reach a maximal effect. Wang et al. (1995) observed that SSC amplitude of natural synapses was increased by the chronic treatment with NT-3, probably resulting from the earlier application of NT-3 at 6-hr-old cultures, when myocyte is still too young to release enough neurotrophins.

The activity of neuromuscular transmission at developing synapses is crucial in synaptic maturation and competition as well as in the differentiation of postsynaptic properties (Lo and Poo, 1991; Balice-Gordon and Lichtman, 1993; Dan and Poo, 1994; Lo and Poo, 1994). The release of neurotrophin may also be activitydependent, as demonstrated in hippocampal neurons (Zafra et al., 1990, 1992). Voltage-gated $\mathrm{Ca}^{2+}$ channels and the nicotinic ACh receptors provide biologically important pathways for $\mathrm{Ca}^{2+}$ influx into postsynaptic muscle cells (Decker and Dani, 1990). Elevation of cytosolic $\mathrm{Ca}^{2+}$ levels in the postsynaptic cell is critical for the induction of many forms of activity-dependent synaptic modulation (Laufer and Changeux, 1989; Dan and Poo, 1992; Lo and 
Poo, 1994). Because ACh receptors are densely packed at the neuromuscular endplate, the $\mathrm{Ca}^{2+}$ influx at active synapses is expected to produce locally high $\mathrm{Ca}^{2+}$ environment. Nuclei of muscle cells associated near the synaptic endplate are different from those distant to synaptic sites (Englander and Rubin, 1987), and synthesis at these nuclei provides a source of molecules that is usable by the endplate (Jasmin et al., 1989). Therefore, $\mathrm{Ca}^{2+}$ influx through ACh receptors is able to provide an activity-dependent signal that regulates processes vital for synaptic plasticity. Our results suggest that the activation of muscle $\mathrm{ACh}$ receptor may increase the release of retrograde factor NT-3. NT-3 thus may modulate the maturation and/or maintenance of presynaptic motor nerve terminals at developing neuromuscular junctions.

\section{REFERENCES}

Anderson MJ, Cohen MW, Zorychta E (1977) Effects of innervation on the distribution of acetylcholine receptors on cultured muscle cells. J Physiol (Lond) 268:731-756.

Balice-Gordon RJ, Lichtman JW (1993) In vivo observations of pre- and postsynaptic changes during the transition from multiple to single innervation at developing neuromuscular junctions. J Neurosci 13:834-855.

Balice-Gordon RJ, Lichtman JW (1994) Long-term synapse loss induced by focal blockade of postsynaptic receptors. Nature 372:519-524.

Barbacid M (1995) Neurotrophic factors and their receptors. Curr Opin Neurobiol 7:148-155.

Bear MF, Malenka RC (1994) Synaptic plasticity: LTP and LTD. Curr Opin Neurobiol 4:389-399.

Berninger B, Poo MM (1996) Fast actions of neurotrophic factors. Curr Opin Neurobiol 6:324-330.

Buchanan J, Sun Y, Poo MM (1989) Studies of nerve-muscle interactions in cell culture: fine structure of early functional contacts. J Neurosci 9:1540-1554.

Chao MV (1992) Neurotrophin receptors: a window into neuronal differentiation. Neuron 9:583-593.

Chow I, Poo MM (1985) Release of acetylcholine from embryonic neurons upon contact with muscle cell. J Neurosci 5:1076-1082.

Connor EA, Smith MA (1994) Retrograde signaling in the formation and maturation of the neuromuscular junction. J Neurobiol 25:722-739.

Cramer KS, Mriganka S (1995) Activity-dependent remodeling of connections in the mammalian visual system. Curr Opin Neurobiol 5:106-111.

Dahm LM, Landmesser LT (1991) The regulation of synaptogenesis during normal development and following activity blockade. J Neurosci 11:238-255.

Dan Y, Poo MM (1992) Hebbian depression of isolated neuromuscular synapse in vitro. Science 256:1570-1573.

Dan Y, Poo MM (1994) Retrograde interactions during formation and elimination of neuromuscular synapses. Curr Opin Neurobiol 4:95-100

Decker ER, Dani JA (1990) Calcium permeability of the nicotinic acetylcholine receptor: the single-channel calcium influx is significant. J Neurosci 10:3413-3420.

Distefano PS, Friedman B, Radziejewski C, Alexander C, Boland P, Schick CM, Lindsay RM, Wiegand SJ (1992) The neurotrophins BDNF, NT-3, and NGF display distinct patterns of retrograde axonal transport in peripheral and central neurons. Neuron 8:983-993.

Eftimie R, Brenner HR, Buonanno A (1991) Myogenin and MyoD join a family of skeletal muscle genes regulated by muscle activity. Proc Natl Acad Sci USA 88:1349-1353.

Englander LL, Rubin LL (1987) Acetylcholine receptor clustering and nuclear movement in muscle fibers in culture. J Cell Biol 104:87-95.

Evers J, Laser M, Sun YA, Xie ZP, Poo MM (1989) Studies of nervemuscle interactions in Xenopus cell culture: analysis of early synaptic currents. J Neurosci 9:1523-1539.

Falls DL, Harris DA, Johnson FA, Morgan MM, Corfas G, Fischbach GD (1990) $\mathrm{Mr} 42,000$ ARIA: a protein that may regulate the accumulation of acetylcholine receptors at developing chick neuromuscular junctions. Cold Spring Harbor Symp Quant Biol 55:397-406.

Fischbach GD, Cohen SA (1973) The distribution of acetylcholine sensitivity over uninnervated and innervated muscle muscle fibers grown in cell culture. Dev Biol 31:147-162.

Fu WM (1995) Regulatory role of ATP at developing neuromuscular junctions. Prog Neurobiol 47:31-44.
Funakoshi H, Belluardo N, Arenas E, Yamamoto Y, Casabona A, Persson H, Ibanez CF (1995) Muscle-derived neurotrophin-4 as an activitydependent trophic signal for adult motor neurons. Science 268:1495-1499.

Goldman D, Brenner HR, Heinemann S (1988) Acetylcholine receptor $\alpha-, \beta-, \gamma-$, and $\delta$-subunit mRNA levels are regulated by muscle activity. Neuron 1:329-333.

Goodman CS, Shatz CZ (1993) Developmental mechanisms that generate precise patterns of neuronal connectivity. Neuron [Suppl] 10:77-98.

Gotz R, Koster R, Winkler C, Raulf F, Lottspeich F, Schartl M, Thoenen $\mathrm{H}$ (1994) Neurotrophin-6 is a new member of the nerve growth factor family. Nature 372:266-269.

Greensmith L, Vrbova G (1989) Effects of muscle paralysis on motoneurone survival in neonatal rats. J Physiol (Lond) 417:148P.

Hall ZW, Sanes JR (1993) Synaptic structure and development: the neuromuscular junction. Neuron [Suppl] 10:99-121.

Hamill OP, Marty A, Neher E, Sakmann B, Sigworth FJ (1981) Improved patch-clamp techniques for high-resolution current recording from cell and cell-free membrane patches. Pflügers Arch 391:85-100.

Henderson CE, Camu W, Mettling C, Gouin A, Poulsen K, Karihaloo M, Rullamas J, Evans T, McMahon SB, Armanini MP, Berkemeier L, Phillips HS, Rosenthal A (1993) Neurotrophins promote motor neuron survival and are present in embryonic limb bud. Nature 363:266-270.

Heumann R (1994) Neurotrophin signalling. Curr Opin Neurobiol $4: 668-679$.

Isackson PJ (1995) Trophic factor response to neuronal stimuli or injury. Curr Opin Neurobiol 5:350-357.

Jasmin BJ, Cartaud J, Bornens M, Changeux J-P (1989) Synaptic plasticity in skeletal muscle: change in the Golgi apparatus distribution during development and after denervation. Soc Neurosci Abstr 15:1351.

Jennings CG, Burden SJ (1993) Development of the neuromuscular synapse. Curr Opin Neurobiol 3:75-81.

Kidokoro Y (1984) Two types of miniature endplate potentials in Xenopus nerve muscle cultures. Neurosci Res 1:157-170.

Kidokoro Y, Yeh E (1982) Initial synaptic transmission at the growth cone in Xenopus nerve-muscle cultures. Proc Natl Acad Sci USA 79:6727-6731.

Kidokoro Y, Anderson MJ, Gruener P (1980) Changes in synaptic potential properties during acetylcholine receptor accumulation and neurospecific interactions in Xenopus nerve-muscle cell culture. Dev Biol 78:464-483.

Klein R, Silos-Santiago I, Smeyne RJ, Lira SA, Brambilla R, Bryant S, Zhang L, Snider WD, Barbacid M (1994) Disruption of the neurotrophin-3 receptor gene trkC eliminates Ia muscle afferents and results in abnormal movements. Nature 368:249-251.

Koliatsos VE, Clatterbuck RE, Winslow JW, Cayouette MH, Price DL (1993) Evidence that brain-derived neurotrophic factor is a trophic factor for motor neurons in vivo. Neuron 10:359-367.

Korsching S (1993) The neurotrophic factor concept: a reexamination. J Neurosci 13:2739-2748.

Lamballe F, Klein R, Barbacid M (1991) trkC, a new member of the trk family of tyrosine protein kinases, is a receptor for neurotrophin-3. Cell 66:967-979.

Laufer R, Changeux J-P (1989) Activity-dependent regulation of gene expression in muscle and neuronal cells. Mol Neurobiol 3:1-53.

Lo YJ, Poo MM (1991) Activity-dependent synaptic competition in vitro: heterosynaptic suppression of developing synapse. Science 254:1019-1022.

Lo YJ, Poo MM (1994) Heterosynaptic suppression of developing neuromuscular synapse in culture. J Neurosci 14:4684-4693.

Lohof AM, Ip NY, Poo MM (1993) Potentiation of developing neuromuscular synapse by the neurotrophins NT-3 and BDNF. Nature 363:350-353.

Lu B, Greengard P, Poo MM (1992) Exogenous synapsin I promotes functional maturation of developing neuromuscular synapses. Neuron 8:521-529.

Mason RT, Peterfreund RA, Sawchenko PE, Corrigan AZ, Rivier JE, Vale WW (1984) Release of the predicted calcitonin gene-related peptide from cultured rat trigeminal ganglion cells. Nature 308:653-655.

Nieuwkoop PD, Faber J (1967) Normal table of Xenopus laevis, 2nd ed. Amsterdam: North-Holland.

Reist NE, Werle MJ, Mcmahan UJ (1992) Agrin released by motor neurons induces the aggregation of acetylcholine receptors at neuromuscular junctions. Neuron 8:865-868. 
Sanes JR, Lawrence JC (1983) Activity-dependent accumulation of basal lamina by cultured rat myotubes. Dev Biol 97:123-136.

Snider WD (1994) Functions of the neurotrophins during nervous system development: what the knockouts are teaching us. Cell 77:627-638.

Spitzer NC, Lamborghini JC (1976) The development of the action potential mechanism of amphibian neurons isolated in cultures. Proc Natl Acad Sci USA 73:1641-1645.

Tabti N, Poo MM (1991) Culturing spinal cord neurons and muscle cells from Xenopus embryos. In: Culturing nerve cells (Banker G, Goslin K eds), pp 137-154. Cambridge, MA: MIT.

Takahashi T, Nakajima Y, Hirosawa K, Nakajima S, Onodera K (1987) Structure and physiology of developing neuromuscular synapses in culture. J Neurosci 7:473-481.

Wang T, Xie K, Lu B (1995) Neurotrophins promote maturation of developing neuromuscular synapses. J Neurosci 15:4796-4805.

Wong V, Arriaga R, Ip NY, Lindsay RM (1993) The neurotrophins BDNF, NT-3, and NT-4/5, but not NGF, upregulate the cholinergic phenotype of developing motor neurons. Eur J Neurosci 5:466-474.
Xie ZP, Poo MM (1986) Initial events in the formation of neuromuscular synapse: rapid induction of acetylcholine release from embryonic neuron. Proc Natl Acad Sci USA 83:7069-7073.

Young SH, Poo MM (1983) Spontaneous release of transmitter from growth cones of embryonic neurones. Nature 305:634-637.

Zafra F, Hengerer B, Leibrock J, Thoenen H, Lindholm D (1990) Activity dependent regulation of BDNF and NGF mRNA in the rat hippocampus is mediated by non-NMDA glutamate receptors. EMBO J 9:3545-3550.

Zafra F, Dastren E, Thoenen H, Lindholm D (1991) Interplay between glutamate and $\gamma$-aminobutyric acid transmitter systems in the physiological regulation of brain-derived neurotrophic factor and nerve growth factor synthesis in hippocampal neurons. Proc Natl Acad Sci USA 88:10037-10041.

Zafra F, Lindholm D, Castren E, Hartikka J, Thoenen H (1992) Regulation of brain-derived neurotrophic factor and nerve growth factor mRNA in primary cultures of hippocampal neurons and astrocytes. J Neurosci 12:4793-4799. 